\title{
Broiler responses to dietary 3,4,5-trihydroxybenzoic acid and oregano extracts under Eimeria challenge conditions
}

Myunghwan $\mathrm{Yu}^{1 \#}$, Jong Oh Jeon ${ }^{1 \#}$, Hyun Min Cho ${ }^{1}$, Jun Seon Hong ${ }^{1}$, Yu Bin Kim ${ }^{1}$, Shan Randima Nawarathne ${ }^{1}$, Samiru Sudharaka Wickramasuriya ${ }^{1}$, Young-Joo $\mathrm{Yi}^{2}$, Hans Lee ${ }^{3}$, Vannie $\mathrm{Wan}^{3}$, Noele Kai Jing $\mathrm{Ng}^{3}$, Chuan Hao Tan $^{3}$ and Jung Min Heo ${ }^{1 *}$

${ }^{1}$ Department of Animal Science and Biotechnology, Chungnam National University, Daejeon 34134, Korea ${ }^{2}$ Department of Agricultural Education, College of Education, Sunchon National University, Suncheon 57922, Korea

${ }^{3}$ Kemin Industries, 758200, Singapore

\section{Abstract}

This study was conducted to evaluate the efficacy of a combination 3,4,5-trihydroxybenzoic acid (THB) and oregano extracts (i.e., Carvacrol and Thymol) at intake/dietary different levels on growth performance, intestinal health indicators, immune responses and fecal oocyst shedding in broiler chickens under Eimeria challenged condition. A total of 336 one-day-old broilers were randomly assigned to one of six dietary treatments with seven replications per treatment. Dietary treatments were: i) Non-challenged bird without any dietary treatment (NCNT), ii) Challenged bird without any dietary treatment (CNT), iii) Challenged birds fed a THB diet (0.1 g/kg, THB), iv) Challenged birds fed a combination of THB and oregano extracts diet $(0.1 \mathrm{~g} / \mathrm{kg}, \mathrm{COM} 100)$, and a gradual increase of combination of THB and oregano extracts likely v) $0.15 \mathrm{~g} / \mathrm{kg}$ (COM 150), and $0.2 \mathrm{~g} / \mathrm{kg}$ (COM 200). On day 14 , all groups except for NCNT have orally challenged with a 10 -fold dose of Livacox ${ }^{\circledR} T$ anticoccidial vaccine to trigger coccidiosis. The results indicated that Eimeria-challenged broilers fed COM 100 and COM 200 diets increased $(p<0.05)$ body weight than CNT diet on day 35. Furthermore, birds fed COM 100 and COM 200 diets increased $(p<0.05)$ average daily gain compared to those fed CNT diets for the entire experimental period. There is no significant $(p>0.05)$ in average daily feed intake, feed efficiency between NCNT and birds fed with combined THB and oregano extracts for the entire experimental period. A combination of THB and oregano extract regardless of concentration levels or THB alone reduced $(p<0.05)$ lesion score in ileum compared to the CNT diet for 7 days post-infection (dpi). Birds fed COM 100 diet had lower $(p<0.05)$ intestinal lesion scores in jejunum and caeca on 7 dpi compared to those were in the CNT diet. No $(p>0.05)$ difference was observed in the oocysts per gram of feces count, intestinal morphology, carcass traits and blood cytokine concentration among the infected treatments. Collectively, we conclude that birds fed with a combination of THB and oregano extracts regardless of the ratios that were used demonstrated better recovery of health after the coccidial challenge than using only THB alone.

Keywords: Broiler, Coccidiosis, Growth performance, Oregano extract, 3,4,5-Trihydroxybenzoic acid 
Shan Randima Nawarathne https://orcid.org/0000-0001-9055-9155

Samiru Sudharaka Wickramasuriya

https://orcid.org/0000-0002-6004-596X

Young-Joo Y

https://orcid.org/0000-0002-7167-5123

Hans Lee

https://orcid.org/0000-0002-8603-947X

Vannie Wan

https://orcid.org/0000-0001-7900-7237

Noele Kai Jing $\mathrm{Ng}$

https://orcid.org/0000-0002-7108-6206

Chuan Hao Tan

https://orcid.org/0000-0003-1270-2686

Jung Min Heo

https://orcid.org/0000-0002-3693-1320

Competing interests

The authors Hans Lee, Vannie Wan,

Noele Kai Jing $\mathrm{Ng}$ and Chuan Hao Tan are employees of Kemin Industries Asia Pte Ltd., declare no conflict of interest.

Funding sources

This work was supported by the Kemin

Industries Asia Pte, Singapore.

\section{Acknowledgements}

The authors are grateful to Kemin Industries Asia Pte, Singapore, for the financial support and the supply of additives used in this study.

Availability of data and material Upon reasonable request, the datasets of this study can be available from the corresponding author.

Authors' contributions

Conceptualization: Lee H, Heo JM.

Data curation: Yu M, Nawarathne SR, Heo JM.

Formal analysis: Yu M, Kim YB, Wan V, Ng NKJ, Heo JM.

Methodology: Yu M, Heo JM.

Software: Yu M, Hong JS, Yi YJ, Heo JM.

Validation: Cho HM, Wickramasuriya SS, Tan $\mathrm{CH}$, Heo JM.

Investigation: Yu M, Jeon JO.

Writing - original draft: Yu M.

Writing - review \& editing: Yu M, Jeon JO, Cho HM, Hong JS, Kim YB, Nawarathne SR, Wickramasuriya SS, Yi YJ, Lee $\mathrm{H}$, Wan V, Ng NKJ, Tan CH, Heo JM.

Ethics approval and consent to participate The experimental procedures were reviewed and approved by the Animal Ethics Committee of the Chungnam National University (202006A-CNU-092)

\section{INTRODUCTION}

Coccidiosis is a major gastrointestinal parasitic disease in the poultry industry and is caused by several Eimeria parasite species [1]. Annually, coccidiosis causes over USD 14.5 billion losses worldwide due to high mortality and its negative effects on growth performance [2].

To control avian coccidiosis, anticoccidial drugs or attenuated vaccines are being used as the most common management practices in the poultry industry [3]. Although anticoccidial products are cost-effective in managing coccidiosis, the occurrence of drug resistance and public demands for antibiotic-free meat has encouraged the development of alternative strategies to manage coccidiosis [4]. Live vaccines are another approach to control coccidiosis, however, they cause severe reactions that may affect the performance of broilers in cases of poor management [5]. Resultingly, attenuated vaccines with reduced pathogenicity have been developed, however, these are costly to produce [6]. Consequently, the use of phytogenics and herbals is an alternative strategy for the safe and effective control of coccidiosis $[7,8]$. These are natural products that have medicinal properties against Eimeria parasites and have not been associated with the development of antimicrobial resistance [9].

The phenolic compound 3,4,5-trihydroxybenzoic acid (THB), also known as gallic acid, is found in several vegetables and fruits [10]. According to previous studies, THB has disease-suppressing biological activities, such as anti-inflammatory, antioxidant, and antibacterial [11-13]. Although THB possesses these benefits, studies that reported the utilization of THB have been limited because of its low bioavailability, poor absorption, and rapid elimination from the body $[14,15]$.

One of the well-established methods for controlling avian coccidiosis is the supplementation of essential oils $[16,17]$. Oregano is a traditional herbal remedy that enhances growth performance and intestinal integrity in broiler chickens with coccidiosis $[7,18,19]$. Carvacrol and thymol of plant-derived essential oils have been analyzed as they exhibit abundant biological properties, including antioxidant, antifungal, antibacterial, and antiprotozoal effects against Eimeria [18,20,21].

To our knowledge, studies on the efficacy of THB treatment and combination THB treatment with oregano extracts on coccidiosis in broilers remain limited. Therefore, our study aimed to investigate and compare the influence of various combinations of THB, and oregano extracts and THB, on growth performance and cocci elimination in broilers for a 35-day post-hatch period. We hypothesized that the properties of THB and oregano extracts, or the synergistic mechanism between THB and oregano extracts, could effectively achieve the anticoccidial effect and improve growth performance in infected broilers.

\section{MATERIALS AND METHODS}

The experimental procedures were reviewed and approved by the Animal Ethics Committee of the Chungnam National University (202006A-CNU-092).

\section{Birds and housing}

A total of 336 one-day-old broiler chickens (Ross 308) were received from the local hatchery (Pyeongtaek, Korea) and housed in raised battery cages $\left(76 \times 61 \times 46 \mathrm{~cm}^{3}\right)$, with similar body weights (BW) and weight distributions $(47.43 \pm 0.05 \mathrm{~g})$. Each pen was equipped with two nipple drinkers and a metal trough. The room temperature was managed according to the Ross 308 broiler management guideline [22]. Birds were offered the experimental diets on an ad libitum basis and had free access to fresh clean drinking water via nipple drinkers throughout the experimental period. The lighting was continuous for 24 hours. 


\section{Experimental design, treatments and diets}

Birds were allocated into one of six dietary treatments in a completely randomized design. Each treatment contained seven replicate cages with eight birds per each. Dietary treatments were as follows: i) Non-challenged bird without any dietary treatment (NCNT), ii) Challenged bird without any dietary treatment (CNT), iii) Challenged birds fed a THB diet $(0.1 \mathrm{~g} / \mathrm{kg}$, THB), iv) Challenged birds fed a combination of THB and oregano extracts diet $(0.1 \mathrm{~g} / \mathrm{kg}, \mathrm{COM} 100)$, and a gradual increase of combination of THB and oregano extracts likely v) $0.15 \mathrm{~g} / \mathrm{kg}$ (COM 150), and $0.2 \mathrm{~g} / \mathrm{kg}(\mathrm{COM} 200)$. Diets were formulated based on corn and soybean meal to meet the Ross 308 nutritional specifications [23] (Table 1) to make dietary treatments, the basal diets were with or without supplementing either THB (VANTIPEARLTM 201, Kemin Industries Asia Pte, Senoko Drive, Singapore) alone or THB with oregano extracts (2.3:1 ratio; ORSENTIALTM EXTEND, Kemin Industries Asia Pte). In addition, $\mathrm{Cr}_{2} \mathrm{O}_{3}$ (Chromium oxide powder, > 99.9\% purity, SigmaAldrich, St. Louis, MO, USA) was added as an internal indigestible marker for digestibility analysis in a proportion of $0.3 \%$ to all experimental diets.

Table 1. Composition ( $\mathrm{g} / \mathrm{kg}$, as-fed basis) of the experimental diets

\begin{tabular}{lcc}
\hline \multicolumn{1}{c}{ Item } & Starter feed (Week 1-3) & Grower feed (Week 4-5) \\
\hline Corn & 48.51 & 60.96 \\
Wheat & 8.40 & 4.12 \\
Wheat bran & 4.10 & - \\
Soybean meal 48\% & 31.15 & 27.62 \\
Vegetable oil & 3.30 & 3.30 \\
Limestone & 1.20 & 0.95 \\
Mono-calcium phosphate & 1.65 & 1.39 \\
Salt & 0.30 & 0.35 \\
Vitamin-mineral premix ${ }^{1)}$ & 0.30 & 0.30 \\
Lysine-HCl & 0.34 & 0.30 \\
DL-Methionine & 0.20 & 0.19 \\
L-Threonine & 0.13 & 0.11 \\
L-Cystine & 0.12 & 0.11 \\
Cr ${ }_{2} \mathrm{O}_{3}$ & 0.30 & 0.30 \\
Calculated values ${ }^{2)}$ & & \\
Crude protein (\%) & 22.0 & 20.0 \\
Metabolizable energy (kcal/kg) & 3050 & 3200 \\
Lysine (\%) & 1.40 & 1.20 \\
Methionine (\%) & 0.64 & 0.60 \\
Methinonine + cystine (\%) & 1.00 & 0.93 \\
Calcium (\%) & 0.94 & 0.80 \\
Phosphorus (\%) & 0.43 & 0.37 \\
SID lysine & 1.25 & 1.12 \\
SID methionine & 0.60 & 0.56 \\
SID methionine + cystine & 0.92 & 0.85 \\
\hline
\end{tabular}

1)Provided per kilogram of diet: vitamin A, 12,000 IU; vitamin $\mathrm{D}_{3}, 2,500 \mathrm{IU}$; vitamin $\mathrm{E}, 30 \mathrm{IU}$; vitamin $\mathrm{K}_{3}, 3 \mathrm{mg}$; D-pantothenic acid, $15 \mathrm{mg}$; nicotinic acid, $40 \mathrm{mg}$; choline, $400 \mathrm{mg}$; and vitamin $\mathrm{B}_{12}, 12 \mu \mathrm{g}$; $\mathrm{Fe}, 90 \mathrm{mg}$ from iron sulfate; $\mathrm{Cu}, 8.8 \mathrm{mg}$ from copper sulfate; $\mathrm{Zn}, 100 \mathrm{mg}$ from zinc oxide; $\mathrm{Mn}, 54 \mathrm{mg}$ from manganese oxide; I, $0.35 \mathrm{mg}$ from potassium iodide; Se, $0.30 \mathrm{mg}$ from sodium selenite.

${ }^{2}$ The values were calculated based on the values of feedstuffs in [24] to meet or exceed the [23].

SID, standardized ileal digestible. 


\section{Growth performance evaluation}

BW of the birds were recorded individually on day 1 of the experiment and designated at the initial BW. Subsequently, BW and feed intake were measured on day 7, 14, 21, 28 and 35. Based on the measured BW and feed intake data, average daily gain (ADG), average daily feed intake (ADFI) including mortality correction, and feed conversion ratio (FCR) were calculated on a pen basis.

\section{Coccidiosis challenge}

All the experimental groups except the NCNT group were challenged by tenfold overdosing of recommended dosage of (LIVACOX ${ }^{\circledR}$ T, Biopharm, Prague, Czech Republic) live vaccine on day 14. One milliliter of inoculum (i.e., $0.1 \mathrm{~mL}$ of vaccine with $0.9 \mathrm{~mL}$ of sterile distilled water) was orally gavaged directly into the crop to each bird in the challenged groups while the NCNT were similarly gavaged the same amount of sterile distilled water. According to manufacturer specification, the LIVACOX ${ }^{\circledR} \mathrm{T}$ vaccine containing live oocysts of Eimeria acevulina, E. maxima and E. tenella strains.

\section{Post-mortem procedure and sample collection}

Seven birds per treatment that closer to the mean BW was selected, fasted and euthanized by cervical dislocation for sample collection on day 18, 21 and 35. The dressing percentage of meat with giblets (i.e., heart, gizzard and liver) was calculated by dividing it by the live weight of the birds. Drumsticks (skinless) and breast meat were removed from carcasses and weighed. The percentages of breast meat and drumstick were calculated as a percentage of the relative carcass weight of broilers [25].

Blood sample collections were carried out on days 18 and 21 of the experiment. Blood samples were collected from the brachial vein into a vacutainer coated with lithium heparin (BD Vacutainer, BD, Franklin Lakes, NJ, USA) before euthanizing the birds. Collected blood samples were quickly transferred to a laboratory for plasma separation.

Abdominal incisions were made on each sacrificed bird and the ileum was separated from the gastrointestinal tract. The ileum was defined as the segment of the small intestine that extended from Meckel's diverticulum to the ileocecal junction [26]. The removed ileal samples $(3 \mathrm{~cm}$ piece) were flushed with ice-cold phosphate-buffered saline (PBS, pH 7.4) and placed into plastic containers that contained $10 \%$ formaldehyde for fixation and stored until microscopic slide preparation $[27,28]$. The remaining digesta of the ileal segment was gently stripped into labeled plastic containers and quickly stored at $-20^{\circ} \mathrm{C}$ freezer until further analysis.

\section{Sample preparation and laboratory analyses}

Collected blood samples were centrifuged (LABOGENE 1248R, Gyrozen, Daejeon, Korea) at $3,000 \times \mathrm{g}$ for $10 \mathrm{~min}$ at $4^{\circ} \mathrm{C}$ and the plasma was separated and stored at $-80^{\circ} \mathrm{C}$ (UniFreez U 400, DAIHAN Scientific, Wonju, Korea) until analysis. The concentrations of interleukin $1 \beta$ (IL-1 $\beta$ ), IL-10, interferon-gamma (IFN- $\gamma$ ), tumor necrosis factor $\alpha(\mathrm{TNF}-\alpha)$ in plasma were quantified using commercially available ELISA kits (MyBioSource, San Diego, CA, USA) according to the manufacturers' instructions described by [29,30].

To analyze the ileal morphometry we followed the method described by [31]. Briefly, ileal samples fixed in $10 \%$ formaldehyde were used for sample preparation. Ring-shaped ileal tissue samples, six diagonal histological sections $(4-6 \mu \mathrm{m})$, were excised and dehydrated, followed by impregnation in paraffin wax. The height of 10 well-align villi and their associated crypts were observed with an inverted microscope (Eclipse TE2000, Nikon Instruments, Tokyo, Japan) and the height and width of the villi and the deep of the crypts were measured through the analysis 
of images of histological sections made from the computerized image-capture software (NISElements Viewer software, Version: 4.20, NIS Elements, Nikon). The height of the villi is defined as the distance from their tip to the base and the width of the villi was measured at the half-height point. The depth of the crypt was defined as the distance from the top of the crypt to muscularis mucosa [32].

\section{Intestinal lesion scoring}

Before ileal samples were collected, one bird from each pen was examined for the presence and the degree of coccidiosis lesion. Lesion scores in the experimental broilers were determined from observing lesions in the digestive tract including jejunum (from the insertion of the duodenal mesentery to the Meckel's diverticulum), ileum and caeca. In general, lesions in these regions correspond grossly to natural predilection sites for E. acervulina, E. maxima, and E. tenella, respectively. Based on the seriousness of the lesions, a scale of 0 (no lesions), 1 (mild lesions), 2 (moderate lesions), 3 (severe lesions) or 4 (extremely severe lesions) was recorded for each chicken according to the estimation by [33].

\section{Oocysts shedding}

On days 7, 8, 9, 10 and 11 post-infection, excreta (free from feathers and feed) was collected per cage for oocyst counting and kept in separate airtight plastic bags. Sample bags were stored at $4{ }^{\circ} \mathrm{C}$ until analysis. The Oocysts per gram feces (OPG) count was measured using the McMaster method of [34] and the procedures by [34] with adjustment. In summary, $4 \mathrm{~g}$ of fecal sample was put in a $56 \mathrm{~mL}$ saturated salt solution (floatation solution) and the mixture was filtered carefully. Then, the filtrate was loaded into both chambers of the McMaster counting slide using a micropipette and kept for five minutes before counting. The number of oocysts in the chambers was counted separately by observing under a $10 \times 10$ magnification compound microscope (Eclipse, TE 2000, Nikon Instruments). The OPG count in each replicate was calculated by multiplying the number of oocysts counted in the McMaster chambers by the factor 50 and the final results were expressed as $\log 10$ oocysts count per gram of feces for each treatment [35,36].

\section{Statistical analyses}

Data were analyzed according to a completely randomized design, using a general linear model (GLM) procedure of one-way ANOVA of SPSS software (Version 26; IBM SPSS 2019, IBM, Armonk, NY, USA). A single pen was used as the experimental unit for all growth performance measurements and OPG counting. Selected individual birds were considered as the experimental unit for the proportion of carcass trait weights, blood cytokines, ileal morphology, and lesion score. When treatment effects were significant $(p<0.05)$, means were separated using Tukey's multiple range test procedures of SPSS software.

\section{RESULTS}

\section{Growth performance}

The effects of dietary THB and oregano supplementation on the growth performance of Eimeriachallenged broiler chickens from hatching to 35 days post-hatch are presented in Table 2. There was no difference $(p>0.05)$ in the BW of broilers from days 1 to 14 . However, all Eimeria-challenged broilers (after day 14$)$ had reduced BW $(p<0.05)$ compared to NCNT. On day 35, birds fed COM 100 and COM 200 diets had improved BW $(p<0.05)$.

Birds in CNT showed a lower ADG compared to NCNT birds from day 15 to 35 following 
Table 2. Effect of dietary 3,4,5-trihydroxybenzoic acid and oregano supplementation on growth performance of coccidiosis challenged broiler chickens $^{11}$

\begin{tabular}{|c|c|c|c|c|c|c|c|c|}
\hline \multirow{2}{*}{ Period } & \multicolumn{6}{|c|}{ Dietary treatment ${ }^{2}$} & \multirow{2}{*}{ SEM } & \multirow{2}{*}{$p$-value } \\
\hline & NCNT & CNT & THB & COM 100 & COM 150 & COM 200 & & \\
\hline \multicolumn{9}{|l|}{ Body weight (g) } \\
\hline Day 1 & 47.38 & 47.46 & 47.55 & 47.36 & 47.48 & 47.52 & 0.052 & 0.883 \\
\hline Day 7 & 176.21 & 167.55 & 168.38 & 168.52 & 168.02 & 173.98 & 1.073 & 0.068 \\
\hline Day 14 & 441.50 & 425.00 & 428.89 & 445.98 & 440.03 & 445.98 & 4.013 & 0.558 \\
\hline Day 21 & $905.50^{\mathrm{b}}$ & $707.07^{\mathrm{a}}$ & $736.04^{\mathrm{a}}$ & $771.44^{\mathrm{a}}$ & $771.28^{\mathrm{a}}$ & $759.90^{\mathrm{a}}$ & 12.190 & 0.001 \\
\hline Day 28 & $1,481.52^{b}$ & $1,162.39^{\mathrm{a}}$ & $1,195.45^{\mathrm{a}}$ & $1,256.91^{\mathrm{a}}$ & $1,251.84^{\mathrm{a}}$ & $1,252.86^{a}$ & 19.121 & 0.001 \\
\hline Day 35 & $2,090.51^{\mathrm{C}}$ & $1,692.43^{\mathrm{a}}$ & $1,802.57^{\mathrm{ab}}$ & $1,857.08^{b}$ & $1,840.66^{\mathrm{ab}}$ & $1,861.68^{\mathrm{b}}$ & 23.482 & 0.001 \\
\hline \multicolumn{9}{|c|}{ Average daily gain (g/d) } \\
\hline Day 7 & 18.40 & 17.16 & 17.26 & 17.31 & 17.22 & 18.07 & 0.154 & 0.066 \\
\hline Day 14 & 37.90 & 36.78 & 37.22 & 39.64 & 38.86 & 38.86 & 0.524 & 0.624 \\
\hline Day 21 & $66.29^{b}$ & $40.30^{\mathrm{a}}$ & $43.88^{\mathrm{a}}$ & $46.49^{a}$ & $47.32^{\mathrm{a}}$ & $44.85^{\mathrm{a}}$ & 1.502 & 0.001 \\
\hline Day 28 & $82.29^{b}$ & $65.05^{\mathrm{a}}$ & $65.63^{\mathrm{a}}$ & $69.35^{\mathrm{a}}$ & $68.65^{\mathrm{a}}$ & $70.42^{\mathrm{a}}$ & 1.243 & 0.001 \\
\hline Day 35 & $87.00^{b}$ & $75.72^{\mathrm{a}}$ & $86.73^{b}$ & $85.74^{\mathrm{b}}$ & $84.12^{\mathrm{ab}}$ & $86.97^{b}$ & 1.063 & 0.007 \\
\hline Day 1-14 & 28.15 & 26.97 & 27.24 & 28.47 & 28.04 & 28.46 & 0.286 & 0.552 \\
\hline Day 15-35 & $78.52^{\mathrm{c}}$ & $60.35^{\mathrm{a}}$ & $65.41^{\mathrm{ab}}$ & $67.20^{\mathrm{ab}}$ & $66.70^{\mathrm{ab}}$ & $67.42^{b}$ & 1.058 & 0.001 \\
\hline Day 1-35 & $58.38^{\mathrm{c}}$ & $47.00^{\mathrm{a}}$ & $50.14^{\mathrm{ab}}$ & $51.71 b$ & $51.23^{\mathrm{ab}}$ & $51.83^{b}$ & 0.671 & 0.001 \\
\hline \multicolumn{9}{|c|}{ Average daily feed intake (g/d) } \\
\hline Day 7 & $24.17^{\mathrm{a}}$ & $24.26^{\mathrm{ab}}$ & $27.16^{\mathrm{bc}}$ & $27.53^{\mathrm{c}}$ & $28.06^{\mathrm{c}}$ & $27.19^{c}$ & 0.358 & 0.001 \\
\hline Day 14 & 54.87 & 51.82 & 51.26 & 53.73 & 53.20 & 54.62 & 0.668 & 0.569 \\
\hline Day 21 & $93.75^{\mathrm{b}}$ & $73.39^{\mathrm{a}}$ & $73.00^{\mathrm{a}}$ & $65.63^{\mathrm{a}}$ & $72.70^{\mathrm{a}}$ & $70.76^{\mathrm{a}}$ & 1.624 & 0.001 \\
\hline Day 28 & 117.94 & 113.58 & 110.94 & 113.62 & 115.97 & 113.81 & 0.986 & 0.445 \\
\hline Day 35 & $133.42^{\mathrm{ab}}$ & $131.96^{\mathrm{a}}$ & $140.36^{c}$ & $139.42^{\mathrm{ab}}$ & $140.36^{c}$ & $141.26^{c}$ & 1.022 & 0.015 \\
\hline Day 1-14 & 39.52 & 38.04 & 39.21 & 40.63 & 40.63 & 40.91 & 0.439 & 0.393 \\
\hline Day 15-35 & $115.04^{\mathrm{b}}$ & $106.31^{\mathrm{a}}$ & $108.10^{\mathrm{a}}$ & $106.22^{\mathrm{a}}$ & $109.68^{\mathrm{ab}}$ & $108.61^{\mathrm{ab}}$ & 0.756 & 0.003 \\
\hline Day 1-35 & $84.83^{b}$ & $79.00^{\mathrm{a}}$ & $80.54^{\mathrm{ab}}$ & $79.99^{\mathrm{ab}}$ & $82.06^{\mathrm{ab}}$ & $81.53^{\mathrm{ab}}$ & 0.540 & 0.026 \\
\hline \multicolumn{9}{|c|}{ Feed conversion ratio $(\mathrm{g} / \mathrm{g})$} \\
\hline Day 7 & $1.32^{\mathrm{a}}$ & $1.42^{\mathrm{ab}}$ & $1.58^{\mathrm{ab}}$ & $1.59^{b c}$ & $1.64^{c}$ & $1.51^{\mathrm{abc}}$ & 0.026 & 0.001 \\
\hline Day 14 & 1.47 & 1.41 & 1.38 & 1.36 & 1.38 & 1.42 & 0.025 & 0.891 \\
\hline Day 21 & $1.42^{\mathrm{a}}$ & $1.83^{\mathrm{b}}$ & $1.69^{\mathrm{ab}}$ & $1.43^{\mathrm{a}}$ & $1.54^{\mathrm{ab}}$ & $1.60^{\mathrm{ab}}$ & 0.036 & 0.002 \\
\hline Day 28 & $1.44^{\mathrm{a}}$ & $1.75^{\mathrm{b}}$ & $1.70^{\mathrm{b}}$ & $1.65^{\mathrm{ab}}$ & $1.70^{\mathrm{b}}$ & $1.62^{\mathrm{ab}}$ & 0.026 & 0.005 \\
\hline Day 35 & 1.54 & 1.75 & 1.62 & 1.64 & 1.68 & 1.63 & 0.022 & 0.135 \\
\hline Day 1-14 & 1.41 & 1.41 & 1.44 & 1.43 & 1.45 & 1.45 & 0.021 & 0.989 \\
\hline Day 15-35 & $1.47^{\mathrm{a}}$ & $1.76^{c}$ & $1.66^{\mathrm{bc}}$ & $1.59^{\mathrm{ab}}$ & $1.65^{\mathrm{bc}}$ & $1.62^{\mathrm{abc}}$ & 0.020 & 0.001 \\
\hline Day 1-35 & $1.46^{\mathrm{a}}$ & $1.68^{\mathrm{b}}$ & $1.61^{b}$ & $1.55^{\mathrm{ab}}$ & $1.60^{\mathrm{ab}}$ & $1.58^{\mathrm{ab}}$ & 0.017 & 0.002 \\
\hline
\end{tabular}

\footnotetext{
${ }^{11}$ Values are the mean of six replicates per treatment.

${ }^{2)} \mathrm{NCNT}$, non-challenged without any dietary treatment; CNT, challenged without any dietary treatment; THB, CNT with 3,4,5-trihydroxybenzoic acid at $0.1 \mathrm{~g}$ per kg; COM 100 , CNT with combination of THB and oregano extract at $0.1 \mathrm{~g}$ per kg; COM 150, CNT with combination of THB and oregano extract at $0.15 \mathrm{~g}$ per kg; COM 200, CNT with combination of THB and oregano extract at $0.2 \mathrm{~g}$ per $\mathrm{kg}$

${ }^{a-c}$ Values in a row with different superscripts differ significantly $(p<0.05)$.
} 
the Eimeria challenge. Nevertheless, birds fed a COM 200 diet showed higher ADG $(p<0.05)$ than birds fed a CNT diet from day 15 to 35 .

Feeding of COM 150 and COM 200 diets was not significant $(p>0.05)$ in the ADFI of the broilers in the NCNT from day 15 to 35 . Additionally, all birds fed a diet supplemented with THB and/or oregano extracts were not significant $(p>0.05)$ in ADFI with NCNT during the overall experimental period.

Moreover, there was no difference $(p>0.05)$ in feed efficiency between treatments during the starting period before the coccidian challenge. After the challenge, birds fed a diet supplemented with COM 100 had a better FCR $(p<0.05)$ than did the CNTs from day 15 to day 35. Furthermore, broilers fed with combined THB and oregano extracts (i.e., COM 100, COM 150, and COM 200) showed no significant $(p>0.05)$ FCR compared to NCNT during the overall experimental period.

\section{Lesion score}

Data in Table 3 represent the effects of dietary THB and oregano supplementation on separated lesion scores for the jejunum, ileum, and ceca in the broiler digestive tract. Broilers fed COM 100, COM 150, and COM 200 diets showed a lower $(p<0.05)$ lesion score for the jejunum at 4 dpi when compared with coccidiosis-infected broilers. Moreover, broilers fed the COM 100 diet had lower $(p<0.05)$ lesion scores of 0.93 for the jejunum, whereas COM 150 birds had lower $(p<0.05)$ lesion scores of 0.57 for the ileum compared with those of challenged birds at 7 dpi. Furthermore, all birds fed a diet supplemented with THB and/or oregano extracts had lower $(p<0.05)$ lesion scores for the ileum compared with those of CNT at 7 dpi. Additionally, lower $(p<0.05)$ lesion scores of 0.79 for the caeca were observed in the COM 100 group compared to the coccidiosisinfected broilers at 4 dpi.

\section{Oocysts per gram feces count}

The results presented in Table 4 indicate that oocysts are undetected in the excreta obtained from the NCNT group. The oocyst shedding pattern showed an increase $(p<0.05)$ at 7 and 8 dpi for

Table 3. Effect of dietary 3,4,5-trihydroxybenzoic acid and oregano supplementation on lesion score in caeca, jejunum and ileum of coccidiosis challenged broiler chickens ${ }^{1)}$

\begin{tabular}{|c|c|c|c|c|c|c|c|c|}
\hline \multirow{2}{*}{ Period } & \multicolumn{6}{|c|}{ Dietary treatment ${ }^{2}$} & \multirow{2}{*}{ SEM } & \multirow{2}{*}{$p$-value } \\
\hline & NCNT & CNT & THB & COM 100 & COM 150 & COM 200 & & \\
\hline \multicolumn{9}{|l|}{ Jejunum } \\
\hline $7 \mathrm{dpi}$ & $0.00^{\mathrm{a}}$ & $2.00^{\mathrm{C}}$ & $1.14^{\mathrm{bc}}$ & $0.93^{\mathrm{ab}}$ & $1.21^{\mathrm{bc}}$ & $1.64^{\mathrm{bc}}$ & 0.134 & 0.001 \\
\hline \multicolumn{9}{|l|}{ Ileum } \\
\hline \multicolumn{9}{|l|}{ Caeca } \\
\hline 4 dpi & $0.00^{\mathrm{a}}$ & $1.64^{\mathrm{c}}$ & $1.29^{\mathrm{bc}}$ & $0.79^{b}$ & $0.93^{\mathrm{bc}}$ & $1.00^{\mathrm{bc}}$ & 0.102 & 0.001 \\
\hline $7 \mathrm{dpi}$ & $0.00^{\mathrm{a}}$ & $1.79^{c}$ & $1.00^{\mathrm{bc}}$ & $1.43^{\mathrm{bc}}$ & $1.14^{\mathrm{bc}}$ & $1.07^{\mathrm{bc}}$ & 0.107 & 0.001 \\
\hline
\end{tabular}

${ }^{11}$ Values are the mean of six replicates per treatment.

${ }^{2)} \mathrm{NCNT}$, non-challenged without any dietary treatment; CNT, challenged without any dietary treatment; THB, CNT with 3,4,5-trihydroxybenzoic acid at 0.1 g per kg; COM 100, CNT with combination of THB and oregano extract at $0.1 \mathrm{~g}$ per kg; COM 150, CNT with combination of THB and oregano extract at $0.15 \mathrm{~g}$ per kg; COM 200, CNT with combination of THB and oregano extract at $0.2 \mathrm{~g}$ per $\mathrm{kg}$.

${ }^{a-c}$ Values in a row with different superscripts differ significantly $(p<0.05)$.

dpi, days post-infection. 
Table 4. Effect of dietary 3,4,5-trihydroxybenzoic acid and oregano supplementation on oocysts per gram in feces of coccidiosis challenged broiler chickens $^{1)}$

\begin{tabular}{|c|c|c|c|c|c|c|c|c|}
\hline \multirow{2}{*}{ Period } & \multicolumn{6}{|c|}{ Dietary treatment ${ }^{2)}$} & \multirow{2}{*}{ SEM } & \multirow{2}{*}{$p$-value } \\
\hline & NCNT & CNT & THB & COM 100 & COM 150 & COM 200 & & \\
\hline \multicolumn{9}{|c|}{ Oocysts per gram count ( $\log _{10}$ Oocysts) } \\
\hline 7 dpi & $0.00^{\mathrm{a}}$ & $4.57^{\mathrm{b}}$ & $4.15^{b}$ & $3.85^{\mathrm{b}}$ & $3.92^{b}$ & $3.53^{\mathrm{b}}$ & 0.384 & 0.001 \\
\hline $8 \mathrm{dpi}$ & $0.00^{\mathrm{a}}$ & $3.83^{b}$ & $4.27^{\mathrm{b}}$ & $3.99^{b}$ & $4.25^{b}$ & $4.02^{b}$ & 0.389 & 0.001 \\
\hline 9 dpi & $0.00^{\mathrm{a}}$ & $3.30^{\mathrm{b}}$ & $3.15^{b}$ & $3.80^{\mathrm{b}}$ & $3.73^{b}$ & $3.71^{b}$ & 0.350 & 0.001 \\
\hline $10 \mathrm{dpi}$ & $0.00^{\mathrm{a}}$ & $3.16^{b}$ & $3.13^{\mathrm{b}}$ & $3.73^{\mathrm{b}}$ & $3.51^{\mathrm{b}}$ & $2.90^{\mathrm{b}}$ & 0.341 & 0.001 \\
\hline $11 \mathrm{dpi}$ & $0.00^{\mathrm{a}}$ & $3.02^{\mathrm{b}}$ & $2.38^{\mathrm{ab}}$ & $2.97^{\mathrm{b}}$ & $2.68^{b}$ & $2.06^{\mathrm{ab}}$ & 0.308 & 0.014 \\
\hline
\end{tabular}

${ }^{11}$ Values are the mean of six replicates per treatment.

${ }^{2)}$ NCNT, non-challenged without any dietary treatment; CNT, challenged without any dietary treatment; THB, CNT with 3,4,5-trihydroxybenzoic acid at 0.1 g per kg; COM 100, CNT with combination of THB and oregano extract at $0.1 \mathrm{~g}$ per kg; COM 150, CNT with combination of THB and oregano extract at $0.15 \mathrm{~g}$ per kg; COM 200 , CNT with combination of THB and oregano extract at $0.2 \mathrm{~g}$ per $\mathrm{kg}$.

${ }^{a, b}$ Values in a row with different superscripts differ significantly $(p<0.05)$.

dpi, days post-infection.

all the other treatments, excluding NCNTs and CNTs. Thereafter, a reduction in oocyte shedding was observed $(p<0.05)$ at 9,10 , and 11 dpi. There was no difference $(p>0.05)$ in the OPG count among the challenged treatments from 7-11 dpi.

\section{Ileal morphology}

The effects of coccidia-challenged broilers fed diets containing different dietary treatments on intestinal morphology are summarized in Table 5. There were no differences $(p>0.05)$ in villus height, crypt depth, and villus height : crypt depth ratio ( $\mathrm{V}: \mathrm{C}$ ratio) of broilers between all treatments at 4 dpi. NCNT birds had a higher villus height $(p<0.05)$ but a shorter crypt depth $(p<0.05)$ at 7 dpi. Consequently, the NCNT group had a higher V:C ratio $(p<0.05)$ among all treatments.

Table 5. Effect of dietary 3,4,5-trihydroxybenzoic acid and oregano supplementation on intestinal morphology of coccidiosis challenged broiler chickens $^{1)}$

\begin{tabular}{|c|c|c|c|c|c|c|c|c|}
\hline \multirow{2}{*}{ Period } & \multicolumn{6}{|c|}{ Dietary treatment ${ }^{2)}$} & \multirow{2}{*}{ SEM } & \multirow{2}{*}{$p$-value } \\
\hline & NCNT & CNT & THB & COM 100 & COM 150 & COM 200 & & \\
\hline \multicolumn{9}{|l|}{ Villus height $(\mu \mathrm{m})$} \\
\hline $4 \mathrm{dpi}$ & 873.25 & 743.82 & 810.59 & 785.06 & 754.67 & 812.24 & 17.330 & 0.308 \\
\hline $7 \mathrm{dpi}$ & $877.45^{b}$ & $427.76^{a}$ & $577.46^{a}$ & $581.74^{\mathrm{a}}$ & $508.52^{\mathrm{a}}$ & $540.85^{a}$ & 33.207 & 0.001 \\
\hline \multicolumn{9}{|l|}{ Crypt depth $(\mu \mathrm{m})$} \\
\hline $4 \mathrm{dpi}$ & 123.28 & 127.04 & 143.64 & 124.05 & 116.49 & 123.34 & 3.322 & 0.281 \\
\hline $7 \mathrm{dpi}$ & $89.21^{a}$ & $263.91^{b}$ & $208.07^{b}$ & $249.08^{b}$ & $254.70^{b}$ & $237.39^{b}$ & 13.300 & 0.001 \\
\hline \multicolumn{9}{|c|}{ Villus height : Crypt depth ratio (V : C) } \\
\hline $4 \mathrm{dpi}$ & 7.38 & 6.07 & 5.83 & 6.53 & 6.65 & 6.92 & 0.210 & 0.322 \\
\hline $7 \mathrm{dpi}$ & $10.18^{\mathrm{b}}$ & $1.66^{\mathrm{a}}$ & $2.99^{\mathrm{a}}$ & $2.63^{\mathrm{a}}$ & $2.04^{\mathrm{a}}$ & $2.39^{\mathrm{a}}$ & 0.633 & 0.001 \\
\hline
\end{tabular}

${ }^{1)}$ Values are the mean of six replicates per treatment.

${ }^{2)} \mathrm{NCNT}$, non-challenged without any dietary treatment; CNT, challenged without any dietary treatment; THB, CNT with 3,4,5-trihydroxybenzoic acid at 0.1 g per kg; COM 100, CNT with combination of THB and oregano extract at $0.1 \mathrm{~g}$ per kg; COM 150, CNT with combination of THB and oregano extract at $0.15 \mathrm{~g}$ per kg; COM 200 , CNT with combination of THB and oregano extract at $0.2 \mathrm{~g}$ per $\mathrm{kg}$.

a,b Values in a row with different superscripts differ significantly $(p<0.05)$.

dpi, days post-infection. 


\section{Blood parameters}

The effects of the experimental treatments on blood cytokine concentrations in broiler chickens at 4 and 7 dpi are presented in Table 6. There were no differences $(p>0.05)$ in blood cytokine concentrations between dietary treatments at 4 and $7 \mathrm{dpi}$.

\section{Carcass traits}

There were no differences $(p>0.05)$ in dressing percentage and relative breast meat weight of broilers between dietary treatments at 4, 7, and $21 \mathrm{dpi}$ (Table 7). The relative drumstick weight was not significantly different $(p>0.05)$ among dietary treatments at 4,7 , and 21 dpi.

\section{DISCUSSION}

The present study was designed to investigate the effects of THB and oregano extracts on growth performance, lesion score, OPG count, blood cytokine concentrations, intestinal morphology, and carcass traits in coccidia-infected broilers. To date, there are few publications on the use of THB as a mitigant treatment for coccidiosis in the diet of broiler chicks. Considering the severity of coccidiosis and the shortcomings associated with anticoccidial drugs or vaccines, any effort made toward improving poultry husbandry conditions without using anticoccidial drugs or vaccines would be of fundamental importance to the production of poultry chains.

As hypothesized, our results showed that broilers challenged with coccidian protozoa adversely affected growth performance. After exposure to Eimeria spp., although there were no significant differences in growth performance indices, such as ADG and ADFI, among those fed with a diet supplemented with THB and/or oregano extracts, all diets containing THB and a combination of THB and oregano extracts (COM 100, COM 150, and COM 200) improved ADG from day 15 to 35. In particular, broilers fed COM 100 and COM 200 had higher ADG during the overall experimental period. The performance of these birds was closer to the results of the NCNT group, and a similar finding was reported by [37], who stated that broilers fed commercial diets with $10 \%$ polyphenolic extract improved the ADG of coccidiosis-infected chicks over the entire experimental

Table 6. Effect of dietary 3,4,5-trihydroxybenzoic acid and oregano supplementation on blood cytokine concentration of coccidiosis challenged broiler chickens ${ }^{1)}$

\begin{tabular}{|c|c|c|c|c|c|c|c|c|}
\hline \multirow{2}{*}{ Period } & \multicolumn{6}{|c|}{ Dietary treatment ${ }^{2)}$} & \multirow{2}{*}{ SEM } & \multirow{2}{*}{$p$-value } \\
\hline & NCNT & CNT & THB & COM 100 & COM 150 & COM 200 & & \\
\hline \multicolumn{9}{|l|}{$4 \mathrm{dpi}$} \\
\hline $\mathrm{IL}-1 \beta(\mathrm{ng} / \mathrm{mL})$ & 1.67 & 8.58 & 8.47 & 7.49 & 7.55 & 8.27 & 1.225 & 0.588 \\
\hline IL-10 (ng/mL) & 6.20 & 8.14 & 8.14 & 7.16 & 7.86 & 7.94 & 1.526 & 0.999 \\
\hline IFN-Y (ng/mL) & 2.21 & 4.44 & 4.02 & 3.61 & 3.86 & 3.93 & 0.552 & 0.914 \\
\hline TNF- $\alpha(p g / m L)$ & 13.62 & 22.50 & 20.20 & 18.00 & 18.45 & 18.91 & 2.582 & 0.964 \\
\hline \multicolumn{9}{|l|}{$7 \mathrm{dpi}$} \\
\hline $\mathrm{IL}-1 \beta(\mathrm{ng} / \mathrm{mL})$ & 6.21 & 11.65 & 9.46 & 10.73 & 9.88 & 10.65 & 1.306 & 0.899 \\
\hline IL-10 (ng/mL) & 16.96 & 16.82 & 19.07 & 15.65 & 18.36 & 18.15 & 2.013 & 0.998 \\
\hline IFN- $\mathrm{Y}(\mathrm{ng} / \mathrm{mL})$ & 1.96 & 4.42 & 3.82 & 3.76 & 4.21 & 4.44 & 0.599 & 0.867 \\
\hline TNF- $\alpha(p g / m L)$ & 6.48 & 9.70 & 7.63 & 6.54 & 7.07 & 7.38 & 1.014 & 0.959 \\
\hline
\end{tabular}

${ }^{11}$ Values are the mean of six replicates per treatment.

${ }^{2)} \mathrm{NCNT}$, non-challenged without any dietary treatment; CNT, challenged without any dietary treatment; THB, CNT with 3,4,5-trihydroxybenzoic acid at 0.1 g per kg; COM 100, CNT with combination of THB and oregano extract at $0.1 \mathrm{~g}$ per kg; COM 150, CNT with combination of THB and oregano extract at $0.15 \mathrm{~g}$ per kg; COM 200 , CNT with combination of THB and oregano extract at $0.2 \mathrm{~g}$ per $\mathrm{kg}$.

dpi, days post-infection; IL-1 $\beta$, interleukin-1 beta; IL-10, interleukin-10; IFN-y, interferon-gamma; TNF- $\alpha$, tumor necrosis factor-alpha. 
Table 7. Effect of 3,4,5-trihydroxybenzoic acid and oregano supplementation on dressing percentage, relative breast meat weight and relative drumstick weight of coccidiosis challenged broiler chickens ${ }^{1)}$

\begin{tabular}{|c|c|c|c|c|c|c|c|c|}
\hline \multirow{2}{*}{ Period } & \multicolumn{6}{|c|}{ Dietary treatment ${ }^{2)}$} & \multirow{2}{*}{ SEM $^{3)}$} & \multirow{2}{*}{$p$-value } \\
\hline & NCNT & CNT & THB & COM 100 & COM 150 & COM 200 & & \\
\hline \multicolumn{9}{|c|}{ Dressing ratio ${ }^{4}(\%)$} \\
\hline $7 \mathrm{dpi}$ & 88.00 & 88.45 & 87.99 & 88.25 & 87.66 & 88.02 & 0.149 & 0.763 \\
\hline $21 \mathrm{dpi}$ & 92.26 & 92.65 & 91.87 & 91.02 & 92.49 & 92.17 & 0.251 & 0.484 \\
\hline $7 \mathrm{dpi}$ & 23.55 & 22.57 & 24.31 & 23.96 & 24.39 & 23.45 & 0.199 & 0.069 \\
\hline $21 \mathrm{dpi}$ & 26.40 & 26.24 & 25.53 & 25.80 & 25.42 & 25.76 & 0.288 & 0.928 \\
\hline \multicolumn{9}{|c|}{ Relative drumstick weight ${ }^{6)}(\%)$} \\
\hline $4 \mathrm{dpi}$ & 9.97 & 9.68 & 9.71 & 10.01 & 9.74 & 9.92 & 0.067 & 0.592 \\
\hline
\end{tabular}

${ }^{11}$ Values are the mean of six replicates per treatment.

${ }^{2)} \mathrm{NCNT}$, non-challenged without any dietary treatment; CNT, challenged without any dietary treatment; THB, CNT with 3,4,5-trihydroxybenzoic acid at 0.1 g per kg; COM 100, CNT with combination of THB and oregano extract at $0.1 \mathrm{~g}$ per kg; COM 150, CNT with combination of THB and oregano extract at $0.15 \mathrm{~g}$ per kg; COM 200 , CNT with combination of THB and oregano extract at $0.2 \mathrm{~g}$ per $\mathrm{kg}$.

${ }^{3)}$ Pooled standard error of the mean.

${ }^{4)}$ (Carcass weight / Live body weight) $\times 100$.

${ }^{5)}$ (Breast meat weight / Carcass weight) $\times 100$.

${ }^{6)}$ (Drumstick weight / Carcass weight) $\times 100$.

${ }^{a, b}$ Values in a row with different superscripts differ significantly $(p<0.05)$.

dpi, days post-infection.

period. [38] reported that $1.0 \%$ of the dietary Galla Rhois containing various tannin-derived components, including methyl gallate and gallic acid, improved ADG of coccidiosis-infected chicks at 5 and $10 \mathrm{dpi}$. Moreover, previous studies by $[7,18]$ reported improved growth performance of infected broiler chickens receiving diets containing carvacrol and thymol compared with the infected control group. Phenolic compounds (i.e., gallic acid), oregano, and its key components (i.e., carvacrol and thymol) preserved gut integrity while stimulating endogenous digestive enzyme secretion of bile, mucus, and saliva, which boosts digestion, leading to enhanced growth performance, as observed in infected broilers $[39,40]$. Therefore, it is possible that the improved growth performance observed in the birds fed a diet with a combination of THB and oregano extracts in the present study may be due to the effects of individual components and synergistic mechanisms between the mixed components.

The use of polyphenolic extracts and oregano extracts to reduce the severity of gut lesions caused by Eimeria spp. has been reported in several studies [18,19,37]. In the current study, we observed that supplemental THB and combinations of THB and oregano extracts had beneficial effects on gut lesion scores in challenged broilers with coccidiosis Eimeria. This observation might be related to the antioxidative properties of the compounds used (i.e., individual THB and combinations of THB and oregano extracts). Antioxidants are known to reduce the cytotoxic effect of scavenging reactive oxygen species and supporting host immunomodulatory effects [16]. Furthermore, the antiparasitic properties of carvacrol and thymol might have reduced coccidial oocysts by reducing the coccidiosis-induced lesions [19].

Although there was no effect on the number of oocysts shedding from 7 to $11 \mathrm{dpi}$ among challenged groups, several studies $[3,38,41]$ have demonstrated similar oocyst shedding patterns to 
the current study. In particular, THB and COM 200 showed numerically better OPG counts at 11 dpi compared with those of infected broilers. This significant effect of phenolic compounds suggests antibacterial mechanisms. [18] reported that the high lipid solubility and hydrophobicity of carvacrol and thymol led to interaction with the phospholipid bilayer in the Eimeria cell membrane, resulting in a change in membrane permeability for cations such as $\mathrm{H}^{+}$and $\mathrm{K}^{+}$. Consequently, the collapse of the oocyst's cell occurs through energy losses (i.e., ATPase inhibition) and ion leakage (particularly calcium), resulting in water imbalance $[19,42]$. THB exhibited the same mechanisms through similar decreasing results due to its hydrophobic properties [43].

Ileal morphology functions as an indicator of gut health and nutrient absorption capacity in broiler chickens [44]. Villus height, crypt depth, and their ratios (V:C) are the histomorphometric indices that can be used to evaluate the development, condition, and digestive capacity of the small intestine [10,32]. Coccidiosis in broilers disrupts intestinal integrity, causing mucosal and submucosal tissue damage, which shortens the villi and reduces digestive enzyme activities. Consequently, digestion and absorption of nutrients are reduced [45,46]. In this study, dietary THB and incorporation of THB with oregano extracts in the diets resulted in no significant difference in ileal villus height and crypt depth, as well as V:C ratio, among infected broilers. Previous studies by $[47,48]$ reported that feeding oregano essential oils improved the $\mathrm{V}: \mathrm{C}$ ratio compared with coccidial groups, whereas there is scarce information in the literature to verify whether gallic acid could have a significant effect on ileal morphology due to Eimeria spp. infection in broilers.

Coccidiosis challenge or supplementation did not affect any of the cytokine profiles, including proinflammatory cytokines, such as IL- $1 \beta$, IFN- $\gamma$, TNF- $\alpha$, and the anti-inflammatory IL-10. Ultimately, further research related to blood cytokine parameters between induced coccidiosis in broilers is required.

In the present study, at 4, 7, and $21 \mathrm{dpi}$, all treatments showed no difference in dressing percentage or breast meat yield. Moreover, all birds used in the experiments showed no major differences in relative leg meat weight. Nevertheless, the addition of THB and combined THB and oregano extract appeared to increase the relative leg meat weight in infected broilers at 21 dpi. Consistent with our results, an earlier study [7] reported that the addition of herbal components, including carvacrol and thymol, to coccidial-challenged broiler chickens did not affect carcass weight. Alternatively, [49] observed that the addition of oregano essential oil, such as carvacrol and thymol, to broiler diets increased carcass yield. Considering this, further studies related to carcass yield between infected broilers and phenolic compounds are required.

In conclusion, dietary THB and a combination of THB and oregano extract demonstrated significantly better performance and coccidia elimination effect in broiler chickens 35 days posthatch. However, numerically, the combination of THB and oregano extracts, regardless of the ratios used, was better than using THB alone. These findings suggest that single or synergistic anticoccidial effects could be achieved through THB or a combination of THB and oregano extract (i.e., carvacrol and thymol) in challenged broilers.

\section{REFERENCES}

1. Chapman HD. Milestones in avian coccidiosis research: a review. Poult Sci. 2014;93:501-11. https://doi.org/10.3382/ps.2013-03634

2. Blake DP, Knox J, Dehaeck B, Huntington B, Rathinam T, Ravipati V, et al. Re-calculating the cost of coccidiosis in chickens. Vet Res. 2020;51:115. https://doi.org/10.1186/s13567-02000837-2

3. Chand N, Faheem H, Khan RU, Qureshi MS, Alhidary IA, Abudabos AM. Anticoccidial ef- 
fect of mananoligosacharide against experimentally induced coccidiosis in broiler. Environ Sci Pollut Res. 2016;23:14414-21. https://doi.org/10.1007/s11356-016-6600-x

4. Chapman HD, Jeffers TK, Williams RB. Forty years of monensin for the control of coccidiosis in poultry. Poult Sci. 2010;89:1788-801. https://doi.org/10.3382/ps.2010-00931

5. Acharya KP, Acharya N. Alternatives to fight against coccidiosis: a review. Nepal Vet J. 2017;34:152-67.https://doi.org/10.3126/nvj.v34i0.22918

6. Abbas RZ, Colwell DD, Gilleard J. Botanicals: an alternative approach for the control of avian coccidiosis. Worlds Poult Sci J. 2012;68:203-15. https://doi.org/10.1017/S0043933912000268

7. Galli GM, Gerbet RR, Griss LG, Fortuoso BF, Petrolli TG, Boiago MM, et al. Combination of herbal components (curcumin, carvacrol, thymol, cinnamaldehyde) in broiler chicken feed: impacts on response parameters, performance, fatty acid profiles, meat quality and control of coccidia and bacteria. Microb Pathog. 2020;139:103916. https://doi.org/10.1016/j.micpath.2019.103916

8. Qaid MM, Al-Mufarrej SI, Azzam MM, Al-Garadi MA. Anticoccidial effectivity of a traditional medicinal plant, Cinnamomum verum, in broiler chickens infected with Eimeria tenella. Poult Sci. 2021;100:100902.https://doi.org/10.1016/j.psj.2020.11.071

9. Jamil M, Mansoor M, Ali A, Shahzad H, ul Haq R, Awan AA, et al. Role of herbal immunomodulators in control of coccidiosis disease. Pak J Sci Ind Res Biol Sci Ser B Biol Sci. 2017;60:176-82.https://doi.org/10.52763/PJSIR.BIOL.SCI.60.3.2017.176.182

10. Samuel KG, Wang J, Yue HY, Wu SG, Zhang HJ, Duan ZY, et al. Effects of dietary gallic acid supplementation on performance, antioxidant status, and jejunum intestinal morphology in broiler chicks. Poult Sci. 2017;96:2768-75. https://doi.org/10.3382/ps/pex091

11. Jung S, Choe JH, Kim B, Yun H, Kruk ZA, Jo C. Effect of dietary mixture of gallic acid and linoleic acid on antioxidative potential and quality of breast meat from broilers. Meat Sci. 2010;86:520-6. https://doi.org/10.1016/j.meatsci.2010.06.007

12. Bai J, Zhang Y, Tang C, Hou Y, Ai X, Chen X, et al. Gallic acid: pharmacological activities and molecular mechanisms involved in inflammation-related diseases. Biomed Pharmacother. 2021;133:110985. https://doi.org/10.1016/j.biopha.2020.110985

13. Ojeaburu SI, Oriakhi K. Hepatoprotective, antioxidant and, anti-inflammatory potentials of gallic acid in carbon tetrachloride-induced hepatic damage in Wistar rats. Toxicol Rep. 2021;8:177-85. https://doi.org/10.1016/j.toxrep.2021.01.001

14. Shahrzad S, Aoyagi K, Winter A, Koyama A, Bitsch I. Pharmacokinetics of gallic acid and its relative bioavailability from tea in healthy humans. J Nutr. 2001;131:1207-10. https://doi. org/10.1093/jn/131.4.1207

15. Ferruzzi MG, Lobo JK, Janle EM, Cooper B, Simon JE, Wu QL, et al. Bioavailability of gallic acid and catechins from grape seed polyphenol extract is improved by repeated dosing in rats: implications for treatment in Alzheimer's disease. J Alzheimers Dis. 2009;18:113-24. https:// doi.org/10.3233/JAD-2009-1135

16. Idris M, Abbas RZ, Masood S, Rehman T, Farooq U, Babar W, et al. The potential of antioxidant rich essential oils against avian coccidiosis. Worlds Poult Sci J. 2017;73:89-104. https:// doi.org/10.1017/S0043933916000787

17. Hafeez A, Ullah Z, Khan RU, Ullah Q, Naz S. Effect of diet supplemented with coconut essential oil on performance and villus histomorphology in broiler exposed to avian coccidiosis. Trop Anim Health Prod. 2020;52:2499-504. https://doi.org/10.1007/s11250-020-02279-6

18. Giannenas I, Florou-Paneri P, Papazahariadou M, Christaki E, Botsoglou NA, Spais AB. Effect of dietary supplementation with oregano essential oil on performance of broilers after experimental infection with Eimeria tenella. Arch Anim Nutr. 2003;57:99-106. https://doi. 
org/10.1080/0003942031000107299

19. Mohiti-Asli M, Ghanaatparast-Rashti M. Dietary oregano essential oil alleviates experimentally induced coccidiosis in broilers. Prev Vet Med. 2015;120:195-202. https://doi.org/10.1016/ j.prevetmed.2015.03.014

20. Tsinas A, Giannenas I, Voidarou C, Tzora A, Skoufos J. Effects of an oregano based dietary supplement on performance of broiler chickens experimentally infected with Eimeria acervulina and Eimeria maxima.J Poult Sci. 2011;48:194-200. https://doi.org/10.2141/jpsa.010123

21. Rúa J, del Valle P, de Arriaga D, Fernández-Álvarez L, García-Armesto MR. Combination of carvacrol and thymol: antimicrobial activity against Staphylococcus aureus and antioxidant activity. Foodborne Pathog Dis. 2019;16:622-9. https://doi.org/10.1089/fpd.2018.2594

22. Aviagen. Ross 308 broiler management guidelines. Huntsville, AL: Aviagen; 2018.

23. Aviagen. Ross 308 broiler performance objectives. Huntsville, AL: Aviagen; 2019.

24. NRC [National Research Council]. Nutrient requirements of poultry. Washington, DC: National Academies Press; 1994.

25. Ding X, Yang C, Wang P, Yang Z, Ren X. Effects of star anise (Illicium verum Hook. f) and its extractions on carcass traits, relative organ weight, intestinal development, and meat quality of broiler chickens. Poult Sci. 2020;99:5673-80. https://doi.org/10.1016/j.psj.2020.07.009

26. Macelline SP, Wickramasuriya SS, Cho HM, Kim E, Shin TK, Hong JS, et al. Broilers fed a low protein diet supplemented with synthetic amino acids maintained growth performance and retained intestinal integrity while reducing nitrogen excretion when raised under poor sanitary conditions. Poult Sci. 2020;99:949-58. https://doi.org/10.1016/j.psj.2019.10.035

27. Wickramasuriya SS, Kim E, Shin TK, Cho HM, Kim B, Patterson R, et al. Multi-carbohydrase addition into a corn-soybean meal diet containing wheat and wheat by products to improve growth performance and nutrient digestibility of broiler chickens. J Appl Poult Res. 2019;28:399-409. https://doi.org/10.3382/japr/pfz002

28. Wickramasuriya SS, Cho HM, Macelline SP, Kim E, Shin TK, Yi YJ, et al. Effect of calcium stearoyl-2 lactylate and lipase supplementation on growth performance, gut health, and nutrient digestibility of broiler chickens. Asian-Australas J Anim Sci. 2020;33:981-91. https://doi. org/10.5713/ajas.19.0595

29. Piñeiro C, Piñeiro M, Morales J, Andrés M, Lorenzo E, del Pozo M, et al. Pig-MAP and haptoglobin concentration reference values in swine from commercial farms. Vet J. 2009;179:7884. https://doi.org/10.1016/j.tvj1.2007.08.010

30. Shin TK, Yi YJ, Kim JC, Pluske JR, Cho HM, Wickramasuriya SS, et al. Reducing the dietary omega- 6 to omega-3 polyunsaturated fatty acid ratio attenuated inflammatory indices and sustained epithelial tight junction integrity in weaner pigs housed in a poor sanitation condition. Anim Feed Sci Technol. 2017;234:312-20. https://doi.org/10.1016/j.anifeedsci.2017.04.022

31. Wickramasuriya SS, Macelline SP, Cho HM, Hong JS, Park SH, Heo JM. Physiological effects of a tallow-incorporated diet supplemented with an emulsifier and microbial lipases on broiler chickens. Front Vet Sci. 2020;7:583998. https://doi.org/10.3389/fvets.2020.583998

32. Seyyedin S, Nazem MN. Histomorphometric study of the effect of methionine on small intestine parameters in rat: an applied histologic study. Folia Morphol. 2017;76:620-9. https://doi. org/10.5603/FM.a2017.0044

33. Tanweer AJ, Chand N, Saddique U, Bailey CA, Khan RU. Antiparasitic effect of wild rue (Peganum harmala L.) against experimentally induced coccidiosis in broiler chicks. Parasitol Res. 2014;113:2951-60. https://doi.org/10.1007/s00436-014-3957-y

34. Soulsby EJL. Helminths, arthropods and protozoa of domesticated animals. 7th ed. London: Baillière Tindall; 1982. 
35. Mwale M, Masika PJ. Point prevalence study of gastro-intestinal parasites in village chickens of Centane district, South Africa. Afr J Agric Res. 2011;6:2033-8. https://doi.org/10.5897/ AJAR09.495

36. Zajac AM, Conboy GA. Veterinary clinical parasitology. 8th ed. Chichester, West Sussex: Wiley-Blackwell; 2012.

37. Cejas E, Pinto S, Prosdocimo F, Batalle M, Barrios H, Tellez G, et al. Evaluation of quebracho red wood (Schinopsis lorentzii) polyphenolic vegetable extract for the reduction of coccidiosis in broiler chicks. Int J Poult Sci. 2011;10:344-9. https://doi.org/10.3923/ijps.2011.344.349

38. Lee JJ, Kim DH, Lim JJ, Kim DG, Min W, Kim GS, et al. Anticoccidial effect of supplemental dietary Galla Rhois against infection with Eimeria tenella in chickens. Avian Pathol. 2012;41:403-7.https://doi.org/10.1080/03079457.2012.702888

39. Alloui N, Alloui MN, Agabou A. Application of herbs and phytogenic feed additives in poultry production-a review. Glob J Anim Sci Res. 2014;2:234-43.

40. Muthamilselvan T, Kuo TF, Wu YC, Yang WC. Herbal remedies for coccidiosis control: a review of plants, compounds, and anticoccidial actions. Evid-Based Complement Altern Med. 2016;2016:2657981. https://doi.org/10.1155/2016/2657981

41. Ali M, Chand N, Khan RU, Naz S, Gul S. Anticoccidial effect of garlic (Allium sativum) and ginger (Zingiber officinale) against experimentally induced coccidiosis in broiler chickens. J Appl Anim Res. 2019;47:79-84. https://doi.org/10.1080/09712119.2019.1573731

42. Sidiropoulou E, Skoufos I, Marugan-Hernandez V, Giannenas I, Bonos E, Aguiar-Martins $\mathrm{K}$, et al. In vitro anticoccidial study of oregano and garlic essential oils and effects on growth performance, fecal oocyst output, and intestinal microbiota in vivo. Front Vet Sci. 2020;7:420. https://doi.org/10.3389/fvets.2020.00420

43. Pan J, Lian H, Jia H, Li S, Hao R, Wang Y, et al. Ultrasound treatment modified the functional mode of gallic acid on properties of fish myofibrillar protein. Food Chem. 2020;320:126637. https://doi.org/10.1016/j.foodchem.2020.126637

44. Apperson KD, Cherian G. Effect of whole flax seed and carbohydrase enzymes on gastrointestinal morphology, muscle fatty acids, and production performance in broiler chickens. Poult Sci. 2017;96:1228-34. https://doi.org/10.3382/ps/pew371

45. Perez-Carbajal C, Caldwell D, Farnell M, Stringfellow K, Pohl S, Casco G, et al. Immune response of broiler chickens fed different levels of arginine and vitamin $\mathrm{E}$ to a coccidiosis vaccine and Eimeria challenge. Poult Sci. 2010;89:1870-7. https://doi.org/10.3382/ps.2010-00753

46. Amerah AM, Ravindran V. Effect of coccidia challenge and natural betaine supplementation on performance, nutrient utilization, and intestinal lesion scores of broiler chickens fed suboptimal level of dietary methionine. Poult Sci. 2015;94:673-80. https://doi.org/10.3382/ps/pev022

47. Bozkurt M, Ege G, Aysul N, Akşit H, Tüzün AE, Küçükyılmaz K, et al. Effect of anticoccidial monensin with oregano essential oil on broilers experimentally challenged with mixed Eimeria spp. Poult Sci. 2016;95:1858-68. https://doi.org/10.3382/ps/pew077

48. Lee JW, Kim DH, Kim YB, Jeong SB, Oh ST, Cho SY, et al. Dietary encapsulated essential oils improve production performance of coccidiosis-vaccine-challenged broiler chickens. Animals. 2020;10:481. https://doi.org/10.3390/ani10030481

49. Eler G, Gomes AVC, Trindade BS, Almeida LSL, Dilelis F, Cardoso VS, et al. Oregano essential oil in the diet of broilers: performance, carcass characteristics, and blood parameters. S Afr J Anim Sci. 2019;49:753-62. https://doi.org/10.4314/sajas.v49i4.17 